\title{
3. Arts in/as Research Practice
}

\subsection{Lips and Scissors by Rata Gordon Nieuwland}

3.2. Offering space for choice and voice by Amanda Musicka-Williams

3.3. Art making through change by Ange Morgan

3.4. An inquiry into belonging, connection and identity by Marta CallizoGiró

3.5. What is this thing we do? by Wendy Lawson

The key thread in this final group of works, Deb, emerges as the use of arts in/as research practice. The first article explores the use of the arts as creative tools to actively engage participants in research processes toward exploring informed consent. Next therole of the art making process within art therapy to support experiences of change, loss and new identities is considered. Examples from a Masters research thesis demonstrate the use of art as research in an inquiry into belonging, connectedness and identity. Finally two shorter creative pieces open up into a loose holding of reflections on arts in/as research.

The pieces in this section speak to me, Stacey, of the arts as poietic, of growth and curiosity, of diversity and blending in methodologies, of the power of living and emergent forms of inquiry, of intersubjective engagement, of more inclusive research practices, of research that is performative and particular and entangled and hazy, and of embracing paradox and not-knowing. 